\title{
Analysis of heat transfer coefficient inside gun barrel
}

\author{
Putti Abhilash* and M. R. Chopade \\ Department of Mechanical Engineering, SavitribaiPhule Pune University, MIT College of Engineering, Pune, India
}

Accepted 15 June 2016, Available online 20 June 2016, Special Issue-5 (June 2016)

\begin{abstract}
The gun barrel is subjected to high dynamic loads along with very high temperature inputs for a very short period of time in the range of 30-40 milliseconds. Hence the time required for the heat dissipation is very small, which leads to the heat accumulation mostly at $2 \mathrm{~mm}$ below the surface of the gun barrel. This creates high temperature gradients inside the gun barrel. The greater the rate of firing, the greater would be the heat accumulation on the surface. This rate of heat accumulation determines the various factors affecting the performance of the gun barrel like calculation of the cook-off temperature of the gun barrel, amount of wear, rate of deformation, fatigue life of the barrel etc. The paper uses thermochemical approach to calculate the heat transfer coefficient variation in the gun barrel. This data is then used for the calculation of the heat transfer rate in the barrel in further finite element simulations of the gun barrel. Using the pressure and velocity variations across the barrel axis along with the density variations and assuming variable burning rate of the propellant values of the Reynolds number is calculated. Then using the mean value of the Prandtl number of the products and Reynolds number,Nusselt number is calculated, from which heat transfer coefficient is obtained..
\end{abstract}

Keywords: Dynamic loads, high temperatures, cook-off temperature, wear, fatigue life, heat transfer coefficient.

\section{Introduction}

The source of high temperature and dynamic loads in the gun barrel is due to the thermochemical burning of the solid propellant. The burning of the solid propellant takes place in three stages; the burning of the propellant under constant volume till the projectile starts moving in the barrel is the first phase, the movement of the projectile from the start till the end of the barrel is the second phase and the final phase is burning at atmospheric conditions just on the onset of leaving the barrel. Due to all these three phases the pressure varies inside the gun barrel which in turn affects the temperature and other thermal properties of the gases inside the gun barrel which needs to be known before the analysis. The project deals with thermal analysis of $120 \mathrm{~mm}$ tank gun barrel.

\section{Literature Survey}

A lot of research has been done to study the process of heat transfer in a gun barrel and the various phenomena occurring when in operation.

Ercanet al (2012), formulated a thermochemical approach in order to obtain the heat transfer coefficient. The author has used variable burning speed, fluctuating pressure along with wave speed and

${ }^{*}$ Corresponding author: Putti Abhilash density of the combustion gases to calculate the Reynolds and Prandtl numbers along the barrel axis. Using these dimensionless numbers further Nusselt number is calculated and finally the varying heat transfer coefficient along the length of the barrel is found out.

Mehmet et al(2014), studied the unsteady heat transfer problem taking place in the gun barrel. The transient heat transfer coefficient obtained from the interior ballistic theory was used as inputs to calculate the temperature distribution of the machine gun barrel. Later on Finite Difference method was used to find the numerical solution of the governing differential equation of heat transfer.

Yujia Sunet al(2015), investigated the time varying heat transfer nature of a circular pipe subjected to an internally expanding cyclic heat source. The motion of the heat source from inside to outside takes place in a matter of few milli seconds, during which forced heating due to convection takes place. After exiting the pipe natural convective cooling takes place. Using Finite volume approach the varying heat transfer to the pipe is studied during this cyclic thermal loading conditions. The output of the investigation are the temperature response and distributions along with heat flux response have been found out.

Hawet al(2009), considered the interlayer thermal contact resistance between the steel barrel and the chrome coating layer and used the conjugate gradient 
method based on an inverse algorithm for calculating the heat flux at the inner surface.

Wu Yong-hai(2009) , using a material model related to temperature, they calculated the transient temperature field of the gun tube subjected to the action of frequent periodic thermal and pressure pulse.

The influence of both these pulses on the temperature distribution in he gun barrel has been found out.

Mishra et al(2010), presented the numerical approach too calculated the rate of heat transfer and calculated the transient temperature profile using this approach. He then validated using experimental approach using vented vessel experimental setup.

Longmiaoet al(2008), showed how to numerically simulate the transient thermal response of a composite material gun barrel.

Haw-Long et al(2009), simulated the multilayer gun barrel and estimated the heat flux and thermal stresses along with thermal contact resistance.

S. Procházkaet al(2012), analytical and finite element calculations were done to calculate elastic bore displacement, elastic tangential surface strain and powder gas pressure. The propellant gases and thermal load were considered together. The analysis was done in software ANSYS Workbench. The calculations were carried out for $30 \mathrm{~mm}$ ballistic barrel. Kolkertet al(1986), presented a two dimensional, quasi two- phase flow (turbulent viscous and compressible) model to find the spatial and temperature distribution at the inner envelope of and through the barrel and in the gas dynamic flow accompanying the interior ballistic cycle.

Ahmed et al (2004), presented the interior ballistics simulations in $9 \mathrm{~mm}$ small chamber conducted by implementing the process into the mixture multiphase model.

\section{Methodology}

The methodology for this project is as follows:

1. To calculate the heat transfer coefficient from thermochemical approach.

2. Use the analytical results to analyze the thermal stresses using FEA solver.

3. Validation of the simulated results using numerical approach.

\subsection{Calculation of heat transfer coefficient}

The pressure and velocity variations inside the gun barrel taken as inputs for the calculation are obtained from the internal ballistic software output. The pressure and velocity variations is shown below in the Fig. 1 and Fig. 2 below.

The propellant used in the gun barrel is a triple based propellant consisting of Nitro-cellulose $\left(\mathrm{C}_{6} \mathrm{H}_{7} \mathrm{~N}_{3} \mathrm{O}_{11}\right)$, Nitroglycerine $\left(\mathrm{C}_{3} \mathrm{H}_{5} \mathrm{~N}_{3} \mathrm{O}_{9}\right)$, and Nitroguanidine $\left(\mathrm{CH}_{4} \mathrm{~N}_{4} \mathrm{O}_{2}\right)$. The major byproducts of the reaction are $\mathrm{CO}, \mathrm{CO}_{2}, \mathrm{H}_{2}, \mathrm{H}_{2} \mathrm{O}, \mathrm{N}_{2}$. The remaining by products are neglected since their mole fraction is less than $10^{-4}$.

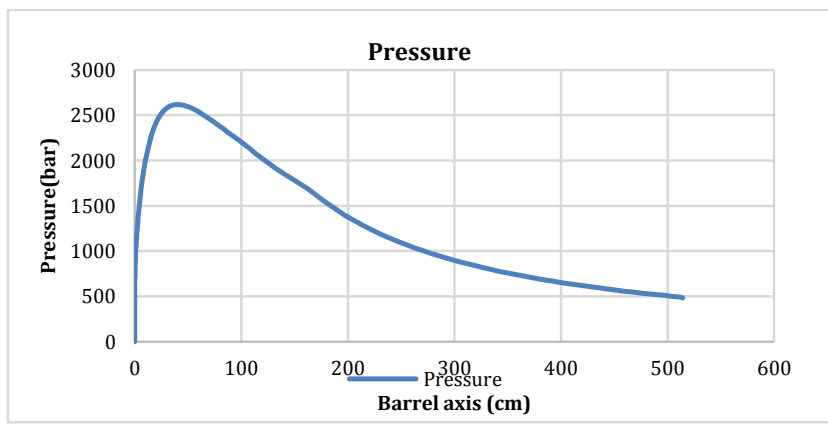

Fig.1 Pressure inside the barrel

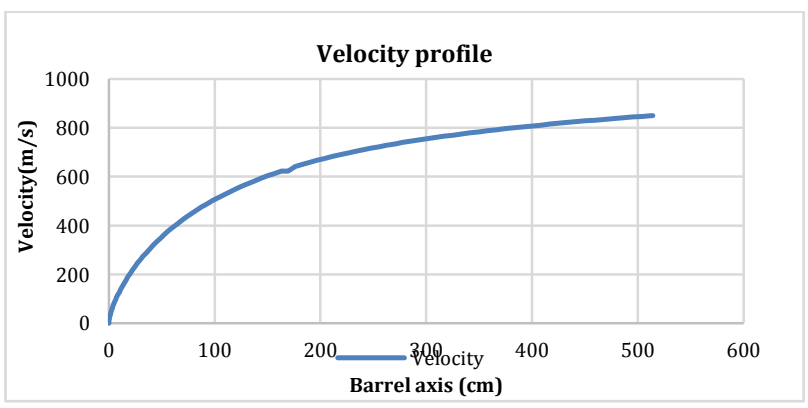

Fig.2 Velocity inside the barrel

The temperature and volume occupied by the gaseous byproducts of combustion under atmospheric conditions are $608.535^{\circ} \mathrm{C}$ and 1214.5886 liters respectively. The temperature $\mathrm{T}_{\mathrm{b}}$ of the gaseous mixture along the barrel axis is calculated using following relation [1]:

$\mathrm{Tb}=\frac{T_{A}}{\left(\frac{P_{A}}{P_{i}}\right)^{\frac{\gamma-1}{\gamma}}}$

Where $P_{i}$ defines the varying barrel pressure along the barrel axis, $P_{A}$ is the atmospheric pressure and $\gamma$ is the ratio of $c_{p}$ and $c_{v}$ of the combustion gases which is taken as 1.236 .

The temperature variation calculated from equation (1) is shown in the Fig.3 below.

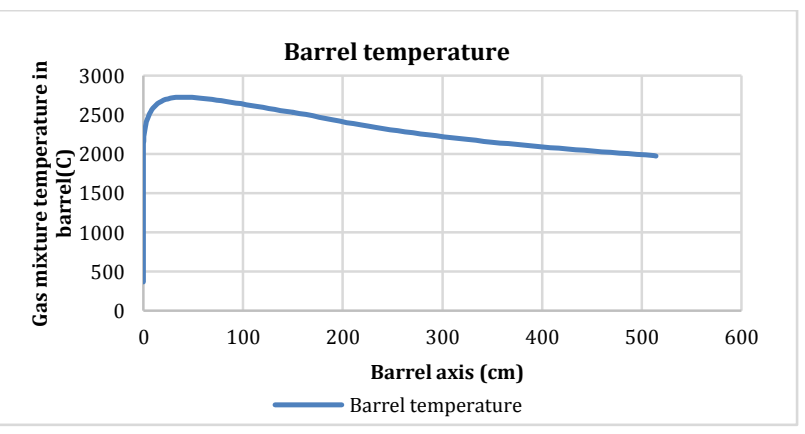

Fig.3 Gas mixture temperature variation along barrel axis 
Reynolds number is calculated from the below equation where $\mathrm{d}$ is $120 \mathrm{~mm}$.

$\mathrm{Re}=\frac{v_{g} d \rho}{\mu_{m}}$

The specific gas constant of the mixture, $\mathrm{Rm}$ is determined from:

$\mathrm{R}_{\mathrm{m}}=\frac{R_{u}}{M_{T}}$

Where $\mathrm{Ru}$ is the universal gas constant $\left(=8314 \mathrm{~m}^{2} / \mathrm{s}^{2} \mathrm{~K}\right)$ $\mathrm{M}_{\mathrm{T}}$ is the molar mass of the mixture $(=22.42)$. Therefore $\mathrm{Rm}$ is determined as $376.8296 \mathrm{~m}^{2} / \mathrm{s}^{2} \mathrm{~K}$.

The varying density $(\rho)$, the varying expansion rate $\left(v_{g}\right)$ is calculated from the equations given below.

$\rho=\frac{P_{i}}{R_{m} T_{b}}$

$v_{g}=c T_{b} P_{i}^{n}$

where $\mathrm{c}$ and $\mathrm{n}$ are taken as 0.00112 and 0.933 respectively.

The value of $\mu_{\mathrm{m}}$ is taken as the mean values of the viscosity of the byproducts. The results of all three factors are shown in the Fig.4, Fig.5, and Fig.6.

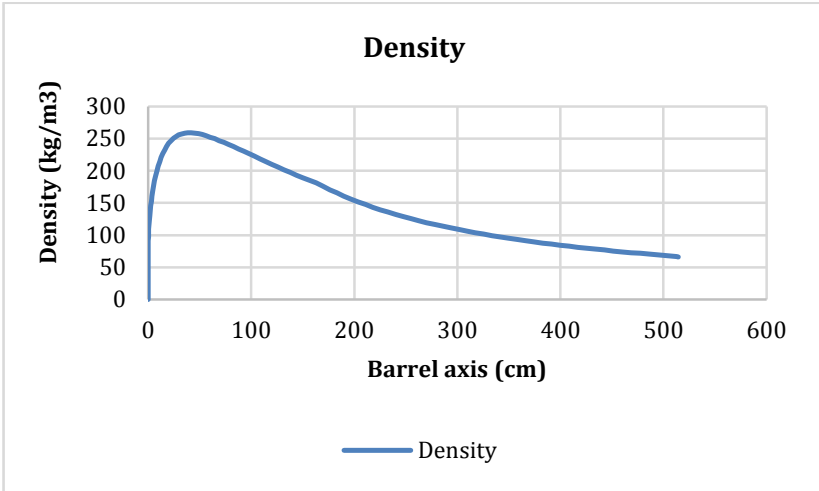

Fig.4 Gas mixture density change along barrel axis

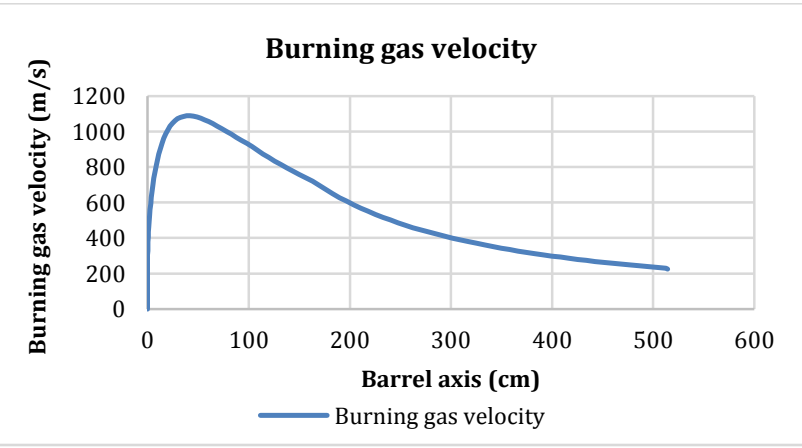

Fig.5 Gas mixture velocity change along barrel axis

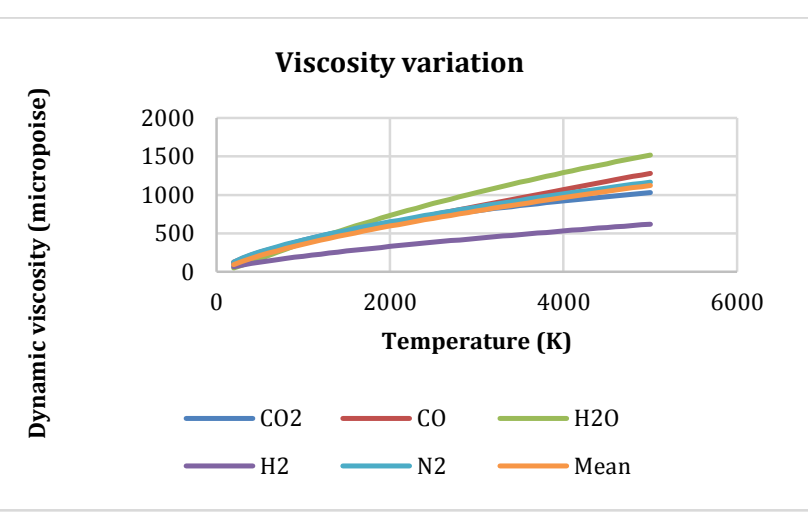

Fig.6 Gas mixture dynamic viscosity change with respect to temperature

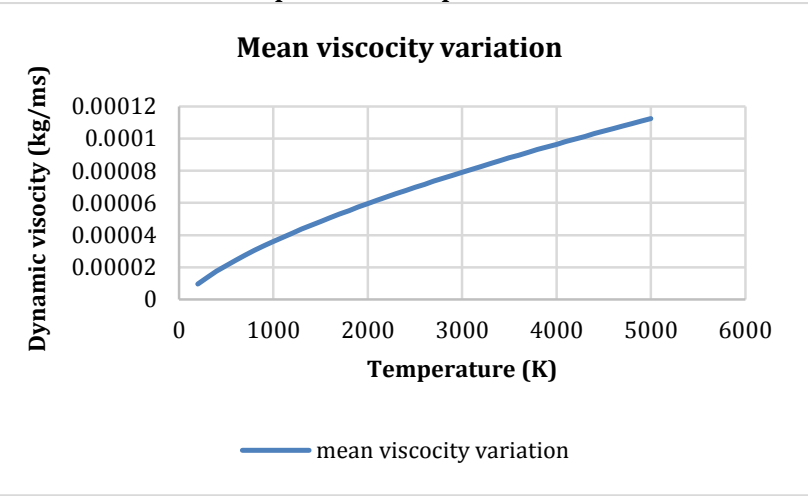

Fig.7 Mean dynamic viscosity variation with respect to temperature

As shown above mean dynamic viscosity variation with respect to temperature is shown in Fig.7. The results of Re obtained from equation (2) is shown below in Fig.8.

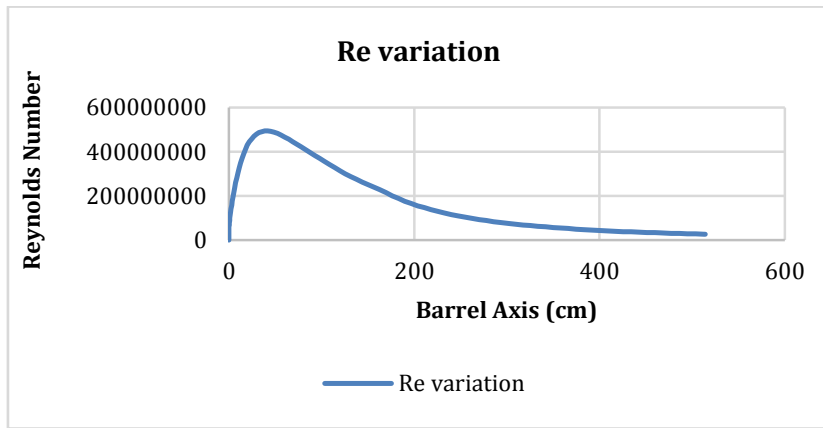

Fig.8. Gas mixture Reynolds number variation along barrel axis

The Prandtl number of the mixture is taken as 0.7

The Nusselt number is calculated from the equation (6) given below:

$\mathrm{Nu}=0.023 \mathrm{Re}^{0.8} \mathrm{Pr}^{0.8}$

With the condition that $\mathrm{Re}>>10000$ and $\mathrm{L} / \mathrm{D} \geq 10$.

The calculated Nusselt number versus Reynolds number is shown in Fig 9. 


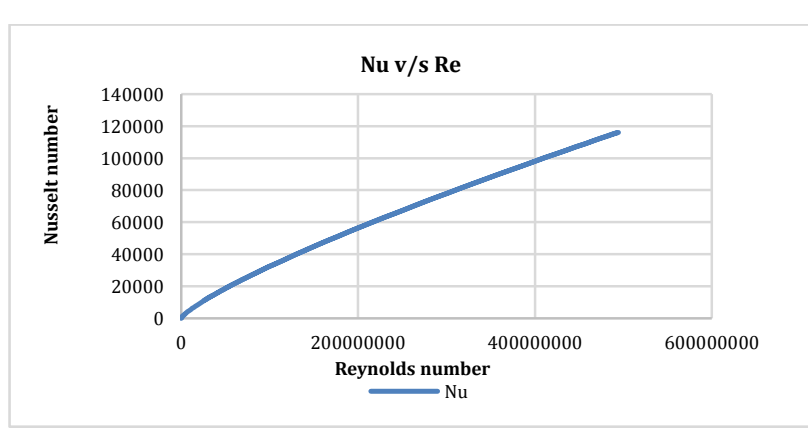

Fig.9Nusselt number of the gaseous mixture inside barrel

The convection heat transfer coefficient variation, $h$, along the barrel axis is found from

$\mathrm{h}=\frac{N u k}{d}$

Considering the varying thermal conductivity of the gaseous mixture the results of the varying heat transfer coefficient are shown in the Fig.12 below.

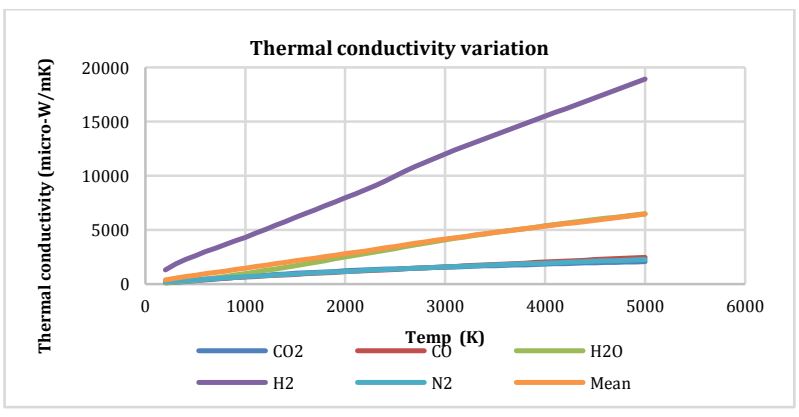

Fig.10 Heat conduction coefficient of the gaseous mixture

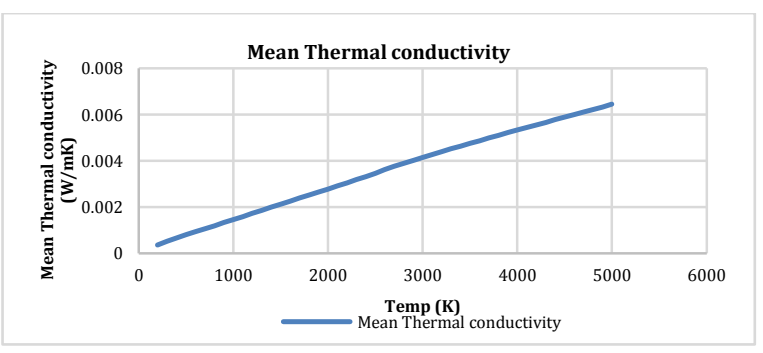

Fig.11 Mean heat conduction coefficient of the gaseous mixture

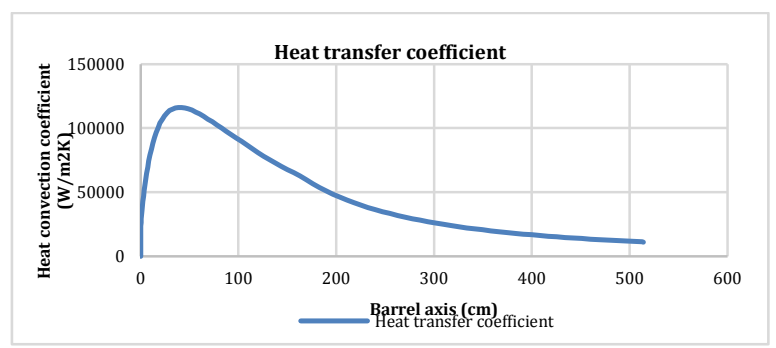

Fig.12 Convection heat transfer coefficient of the gaseous mixture inside barrel

\subsection{Using analytical results to calculate thermal} stresses:

The above calculated heat transfer coefficient will then be used as input to the FEA solver to calculate the temperature profile due to transient behavior and temperature stresses produced in the barrel.

\subsection{Validation using Numerical approach}

The results obtained from simulation will then be validated using the Numerical approach wherein the governing equation will be discretized along with the boundary conditions and the known analytical values will be taken as input to calculate the temperature variation with respect to time.

\section{Conclusions}

The heat transfer coefficient has been calculated using the thermo-chemical approach. The variation of heat transfer coefficient along the barrel axis shows the transient nature of the possible rate of heat transfer thus ensuring the results to be close to the practical approach.

\section{Acknowledgement}

The author would like to thank ARDE,Pashan,Pune for their support.

\section{References}

ErcanDe_girmenci, M. HüsnüDirikolu (2012), A thermochemical approach for the determination of convective heat transfer coefficients in a gun barrel, Applied Thermal Engineering, 37, pg. 275-279.

Mehmet AKÇAY and M. Adil YÜKSELEN (2014), Unsteady thermal studies of gun barrels during the interior ballistic cycle with non- homogenous gun barrel material thermal characteristics, Journal of Thermal Science and Technology, 1300-3615.

Yujia Sun, Xiaobing Zhang (2015), Heat transfer analysis of a circular pipe heated internally with a cyclic moving heat source, International Journal of Thermal Sciences, 90, pg. 279-289.

Tsung-Chien Chen, Chiun-Chien Liu,Horng-Yuan Jang, an-hio Tuan (2007) Inverse estimation of heat flux and temperature in multi- layer gun barrel, International Journal of Heat and Mass Transfer, 50, pg. 2060-2068.

Haw-Long Lee, Yu-Ching Yang, Win-Jin Chang, Tser-Son Wu (2009), Estimation of heat flux and thermal stresses in multilayer gun barrel with thermal contact resistance, Applied Mathematics and Computation, 209, pg. 211-221.

Wu Yong-hai, Analysis of the temperature field of a gun tube based on thermalsolid coupling (2013), Research Journal of Applied Sciences, Engineering and Technology 5

A. Mishra, A. Hameed, B. Lawton, A novel scheme for computing gun barrel temperature history and its experimental validation, Journal of Pressure Vessel Technology. 132(2010) 881-888.

C. Longmiao, L. Qian, Y. Xu, Numerical simulation of transient thermal response of composite material barrel during firing, 2008 Asian Simulation Conference- $7^{\text {th }}$ Intl. Conf. on Sys. Simulation and Scientific Computing pp. 633-637.

Haw-Long lee, Yu-Ching Yang, Win-Ji Chang, Tser-Son Wu, Estimation of heat flux and thermal stresses in multi-layer gun barrel with thermal contact resistance, Appl. Math. Comput. 209(2009) 211-221.

S. Procházka and N. D. Ninh, Differences in Barrel Chamber and Muzzle Deformation during shot, Advances in Military Technology, Vol. 7, No. 2 December 2012

W. J. Kolkert, H.G. The, the thermal behavior of the barrel during the interior ballistic cycle of propellant guns. 9th international Symposium on ballistics, Shrivenham 29th april-1st May 1986

Ahmed Bougamra and Huilin Lu, Multiphase CFD Simulation of Solid Propellant Combustion in a Small Gun Chamber. International Journal of Chemical Engineering,2004. 